\title{
Effective transfer entropy approach to information flow between exchange rates and stock markets 证, 败许
}

\author{
Ahmet Sensoy ${ }^{\mathrm{a}, \mathrm{b}, *}$, Cihat Sobaci ${ }^{\mathrm{a}}$, Sadri Sensoy ${ }^{\mathrm{c}}$, Fatih Alali ${ }^{\mathrm{d}}$ \\ ${ }^{a}$ Borsa Istanbul, Research Department, Emirgan, Istanbul 34467, Turkey \\ ${ }^{\mathrm{b}}$ Bilkent University, Department of Mathematics, Ankara 06800, Turkey \\ ${ }^{\mathrm{c}}$ Bulent Ecevit University, Department of Industrial Engineering, Zonguldak 67100, Turkey \\ d Borsa Istanbul, Futures and Options Market, Emirgan, Istanbul 34467, Turkey
}

\section{A R T I C L E I N F O}

\section{Article history:}

Received 27 April 2014

Accepted 8 August 2014

\begin{abstract}
A B S T R A C T
We investigate the strength and direction of information flow between exchange rates and stock prices in several emerging countries by the novel concept of effective transfer entropy (an alternative non-linear causality measure) with symbolic encoding methodology. Analysis shows that before the 2008 crisis, only low level interaction exists between these two variables and exchange rates dominate stock prices in general. During crisis, strong bidirectional interaction arises. In the post-crisis period, the strong interaction continues to exist and in general stock prices dominate exchange rates.
\end{abstract}

(c) 2014 Elsevier Ltd. All rights reserved.

\section{Introduction}

In recent years, emerging economies have been of vital importance to global investment community for many reasons such as the expectation about their increasing dominance in the international arena and the dramatic changes in the capital flows to their markets. Due to these dramatic changes, financial crises stemming from sudden and unexpected oscillation in stock markets and exchange rates have become a common phenomenon in these economies. This realization makes it essential to investigate the

\footnotetext{
The views expressed in this work are those of the authors and do not necessarily reflect those of the Borsa Istanbul or its members.

An earlier version of this paper was presented at the "20th Annual MFS Conference" organized by Multinational Finance Society in Izmir/ Turkey, June 30-July 3, 2013. We thank conference participants for helpful comments and insightful suggestions.

* Corresponding author at: Borsa Istanbul, Research Department, Emirgan, Istanbul 34467, Turkey. Tel.: +90 21229827 39; fax: +90 212 2982500.

E-mail address: ahmet.sensoy@borsaistanbul.com (A. Sensoy).
}

relationship between these two markets in emerging countries. $^{1}$

The theory on the dependency between exchange rates and stock markets is categorized into three main models: According to flow-oriented approach, exchange rate movements affect international economic activities, thereby influence real economic variables, hence affect costs of a company with considerable exports/imports resulting with an impact on the company's stock price. Stock-oriented approach states that foreign investors are attracted by a persistent increase (decrease) in stock prices leading to capital inflows (outflows) resulting in an appreciation (depreciation) of the local currency. Finally, asset-market approach states that exchange rate is treated like an asset; it's value is determined by the expected future exchange rates and information that affects future value of exchange rate may differ from the ones that cause changes in stock prices.

As it can be anticipated, there is not a common view about the interaction between these two markets.

\footnotetext{
${ }^{1}$ Another reason for selecting emerging economies is that different than developed economies, they also face with currency risk.
} 
Moreover, such an analysis is not easy but crucial, not only for investment and risk management issues, but also for the economic and financial stability.

Early researches approached to the interaction of these two markets by using methods of linear [2] or non-linear Granger [3] causality ${ }^{2}$ and vector error correction ${ }^{3}$ framework. In this paper an alternative methodology using information theoretical concept, transfer entropy (TE) [10], is applied to analyze the information flow between stock markets and exchange rates in emerging countries. Previous implementation of $T E$ in financial literature usually focused on the interaction between individual stocks or between international stock markets $[8,7,6,5,4]$. As far as we know, this is one of the only two studies using TE to analyze the exchange rate and stock market interaction (for the other, see [9]). Furthermore, it analyses the effects of the 2008 global financial crisis on this interaction which has not been studied in detail yet. Our findings have important implications which is discussed in detail in the last section.

The rest of the paper is organized as follows: Section 2 explains the methodology used in this study. Section 3 presents the data and the results of our analysis. Finally, Section 4 includes some discussion and offers a brief conclusion.

\section{Methodology}

The following explains the TE and how we apply it to financial time series. The behavior of a system $X$ can be characterized by looking at the set of states the system visits as it evolves in time. We can express the expectation to find the system in state $x$ in terms of the probability $p(x)$ that it can be found in that state by $s(x)=-\log p(x)$. Averaging this quantity over all possible states $x$ gives a measure of uncertainty of the system: $H(X)=-\sum_{x \in X} p(x) \log p(x) \cdot H(X)$ is called the [12] entropy and the largest amount of uncertainty is observed if all possible values of $\mathrm{X}$ are equally likely. ${ }^{4}$ If the system states can be described by two subsystems $X$ and $Y$, we can use the joint entropy $H(X, Y)=$ $-\sum_{x \in X} \sum_{y \in Y} p(x, y) \log p(x, y)$ to describe the state of the system. If two systems are interacting with each other and we know the outcome of one of them then it may decrease the unpredictability of the other. The idea is the following;

$$
\begin{aligned}
H(X \mid Y) & =-\sum_{y \in Y} p(y) \sum_{x \in X} p(x \mid y) \log p(x \mid y) \\
& =-\sum_{x, y} p(x, y) \log \frac{p(x, y)}{p(y)}
\end{aligned}
$$

where $H(X \mid Y)$ is called the conditional entropy that is the uncertainty of $X$ such that $Y$ is known i.e. $H(X \mid Y)=H(X, Y)-H(Y)$. Another necessary concept to be defined is the mutual information $(M I)$ : $M I$ of two systems $X$ and $Y$ is a quantity that measures the mutual dependence between them and defined as

\footnotetext{
${ }^{2}$ However the conclusions of these methods are limited to the mere existence of information flows rather than their quantification.

${ }^{3}$ Requires co-integrated series but due to market imperfections it is not always satisfied.

4 Note that changing the base of the logarithm changes only the units in which entropy is measured, from now on we take log base as 2 .
}

$M I(X ; Y)=-\sum_{x, y} p(x, y) \log \frac{p(x, y)}{p(x) p(y)}$

Note that, $M I(X ; Y)=H(X)-H(X \mid Y)$ and $M I(X ; Y)=$ $M I(Y ; X)=H(X)+H(Y)-H(X, Y)$. If you know something about the subsystem $X$, the $M I$ describes how much information you also possess about $Y$, and vice versa. While $M I$ is an important quantity in identifying relationships between subsystems, its symmetry property prevents it providing information regarding the causality of their interactions. Recently, [10] introduced an asymmetric innovative information-theoretic quantity TE to overcome this problem.

Assume that $X_{i}$ and $Y_{i}$ are discrete random variables. Define the following random variables of length $k$ and $l$ as $X_{i}^{(k)}=\left(X_{i}, X_{i-1}, \ldots, X_{i-k+1}\right)$ and $Y_{i}^{(l)}=\left(Y_{i}, Y_{i-1}, \ldots, Y_{i-l+1}\right)$ then the transition probabilities can be defined as follows;

$p\left(x_{i+1} \mid x_{i}^{(k)}, y_{i}^{(l)}\right)=\operatorname{prob}\left(X_{i+1}=x_{i+1} \mid X_{i}^{(k)}=x_{i}^{(k)}, Y_{i}^{(l)}=y_{i}^{(l)}\right)$

where $x_{i}^{(k)}=\left(x_{i}, x_{i-1}, \ldots, x_{i-k+1}\right)$ and $y_{i}^{(l)}=\left(y_{i}, y_{i-1}, \ldots, y_{i-l+1}\right)$ are the states of $X_{i}^{(k)}$ and $Y_{i}^{(l)}$ respectively. Eq. (3) denotes the probability of finding $X_{i+1}$ in the state $x_{i+1}$, when $X_{i}^{(k)}$ and $Y_{i}^{(l)}$ are in the states $x_{i}^{(k)}$ and $y_{i}^{(l)}$ respectively. If the future state $x_{i+1}$ of $X_{i}$ depends on the $k$-past states $x_{i}^{(k)}$ and the $l$-past states $y_{i}^{(l)}$, then it can be quantified by TE which is obtained by comparing two conditional entropies;

$$
\begin{aligned}
T E_{Y \rightarrow X}(k, l) & =H\left(X_{i+1} \mid X_{i}^{(k)}\right)-H\left(X_{i+1} \mid X_{i}^{(k)}, Y_{i}^{(l)}\right) \\
& =\sum p\left(x_{i+1}, x_{i}^{(k)}, y_{i}^{(l)}\right) \log \frac{p\left(x_{i+1} \mid x_{i}^{(k)}, y_{i}^{(l)}\right)}{p\left(x_{i+1} \mid x_{i}^{(k)}\right)}
\end{aligned}
$$

so the transfer entropy $T E_{Y \rightarrow X}$ is the information about future of $X_{i}$ gathered from both $X_{i}^{(k)}$ and $Y_{i}^{(l)}$ minus the information retrieved from only $X_{i}^{(k)}$.

We choose the block lengths $k$ and $l$ based on $M I$ between the time series $X$ and its own series with delay $k$ following the suggestion of [1]: as the time delay $k$ is increased, the value $k$ that produces the first local minimum of that $M I$ can be used. Then the choice for $l$ is usually $l=k$.

$T E$ estimates derived in Eq. (4) are likely to be biased due to finite sample effects. To reduce the bias, we use the effective transfer entropy (ETE),

$E T E_{Y \rightarrow X}=T E_{Y \rightarrow X}(k, l)-\frac{1}{M} \sum_{i=1}^{M} T E_{Y_{(i)} \rightarrow X}(k, l)$

where for all $i$, the $Y_{(i)}$ is a shuffled series of $Y^{6}$

\footnotetext{
5 The conditional probabilities in Eq. (4) are estimated over given past empirical data; in particular; by counting the number of desired events and dividing by to total number of events. The estimates on conditional probability performed in such a way are accurate representatives of the true probabilities of a certain state occurring at time $t+1$ given the history up to time $t$, if the history is long enough. To show this, we run a little and simple simulation: We generate 200 binary random variables (heads- $\mathrm{H}$ or tails-T). The outcome of 199 consecutive pairs is as follows: $\mathrm{HH}=47$, $\mathrm{HT}=55, \mathrm{TH}=56$ and $\mathrm{TT}=41$. If we generate 1000 binary random variables, the outcome structure is $\mathrm{HH}=249, \mathrm{HT}=256, \mathrm{TH}=255$ and $\mathrm{TT}=239$.

${ }^{6}$ We use the iterated amplitude adjusted Fourier transform technique [13] to shuffle the series $Y$. The surrogate data sequence generated this way has the same mean, the same variance, the same autocorrelation function, and therefore the same power spectrum as the original sequence $Y$, but (non-linear) phase relations are destroyed.
} 
Table 1

Effective transfer entropies between (symbolic) stock market index and (symbolic) exchange rate series in each period.

\begin{tabular}{|c|c|c|c|c|c|c|}
\hline & \multicolumn{2}{|l|}{ Pre-crisis } & \multicolumn{2}{|l|}{ Crisis } & \multicolumn{2}{|l|}{ Post-crisis } \\
\hline & Index $\rightarrow$ Curr. & Curr. $\rightarrow$ Index & Index $\rightarrow$ Curr. & Curr. $\rightarrow$ Index & Index $\rightarrow$ Curr. & Curr. $\rightarrow$ Index \\
\hline Brazil & -0.004 & 0.006 & $0.067^{* * *}$ & $0.011^{*}$ & $0.021^{*}$ & $0.014^{*}$ \\
\hline Chile & $0.011^{* *}$ & $0.032^{* *}$ & $0.018^{* *}$ & 0.005 & $0.018^{*}$ & -0.001 \\
\hline Czech Republic & $0.023^{* *}$ & 0.008 & $0.016^{* *}$ & $0.027^{* * *}$ & $0.023^{* * *}$ & $0.014^{* * *}$ \\
\hline South Korea & -0.002 & 0.004 & 0.007 & $0.021^{* * *}$ & $0.019^{* *}$ & -0.003 \\
\hline Mexico & 0.002 & -0.003 & -0.002 & $0.109^{* * *}$ & $0.031^{* * *}$ & 0.009 \\
\hline Philippines & 0.01 & 0.003 & $0.017^{* *}$ & -0.000 & 0.005 & $0.044^{* * *}$ \\
\hline Poland & -0.009 & -0.002 & $0.048^{* *}$ & $0.05^{* * *}$ & $0.007^{* *}$ & $0.016^{* *}$ \\
\hline South Africa & -0.008 & 0.002 & -0.008 & $0.023^{* * *}$ & 0.002 & 0.002 \\
\hline Turkey & $0.024^{* *}$ & $0.041^{* * *}$ & $0.032^{* *}$ & $0.021^{* * *}$ & 0.003 & $0.023^{* * *}$ \\
\hline
\end{tabular}

Note: ${ }^{*},{ }^{* *}$ and ${ }^{* * *}$ indicate significance at the $\% 10,5 \%$ and $1 \%$ significance level (obtained from surrogate data).

\section{Data and results}

To have a common ground, we consider all emerging countries implementing inflation targeting as monetary policy and having free-float currencies during the time period of our study, namely; Brazil, Chile, Czech Republic, South Korea, Mexico, Philippines, Poland, South Africa, and Turkey. The aim is to analyze the information flow between exchange rates and stock markets in each of these countries, thus for every country, the daily log-returns of benchmark stock market indexes and exchange rates visa-vis US dollar are considered (tickers of the benchmark indexes and the optimal delays are presented in Table A.1 in the A). Analysis takes place between 2005 and 2012 and time interval is divided into three periods as pre-crisis (January 2005 to July 2007), crisis (August 2007 to March 2009) and post-crisis (April 2009 to September $2012)^{7}$ For synchronization of the data, we consider the days when both stock and foreign exchange markets operate in the relevant country.

To analyze the information flow with ETE, we use the symbolic encoding method: in each period, for each return series $r_{t}$, we construct the corresponding symbolic return series $s_{t}$ as $s_{t}=+1$ if $r_{t}$ belongs to highest $5 \%$ of returns, $s_{t}=-1$ if $r_{t}$ belongs to lowest $5 \%$ of returns and $s_{t}=0$ otherwise. Thus in a symbolic time series, the extreme positive and negative returns are denoted by +1 and -1 respectively. The intermediate bin is kept large to focus on extreme events, which enables us to isolate

\footnotetext{
7 There is not a clear consensus about the start and end date of the crisis period. In our case, we take the starting date as August 9, 2007. On this date, the seizure in the banking system precipitated by BNP Paribas announcing that it was ceasing activity in three hedge funds that specialized in US mortgage debt. This was the moment it became clear that there were tens of trillions of dollars worth of dodgy derivatives swilling round which were worth a lot less than the bankers had previously imagined. For the end date of the crisis period, we take April 2, 2009. At the London G20 summit on this date, world leaders committed themselves to a $\$ 5$ tn fiscal expansion, an extra \$1.1tn of resources to help the International Monetary Fund and other global institutions boost jobs and growth, and to reform of the banks. From this point, the global economy was on the turn. For more on the subject, see http://www.theguardian.com/business/2011/ aug/07/global-financial-crisis-key-stages.
}

Table 2

Net information flow between stock markets and exchange rates.

\begin{tabular}{llll}
\hline & Pre-crisis & Crisis & Post-crisis \\
\hline Brazil & $\mathbf{0 . 0 0 9 7}$ & 0.0565 & 0.007 \\
Chile & $\mathbf{0 . 0 2 1 2}$ & 0.0134 & 0.0187 \\
Czech Republic & 0.0154 & $\mathbf{0 . 0 1 1 5}$ & 0.0083 \\
South Korea & $\mathbf{0 . 0 0 6 2}$ & $\mathbf{0 . 0 1 3 5}$ & 0.0213 \\
Mexico & 0.0047 & $\mathbf{0 . 1 0 9 7}$ & 0.0228 \\
Philippines & 0.0067 & 0.0169 & $\mathbf{0 . 0 3 9 4}$ \\
Poland & $\mathbf{0 . 0 0 7 5}$ & $\mathbf{0 . 0 0 1 3}$ & $\mathbf{0 . 0 0 8 7}$ \\
South Africa & $\mathbf{0 . 0 0 9}$ & $\mathbf{0 . 0 3 0 6}$ & 0.0001 \\
Turkey & $\mathbf{0 . 0 1 7 2}$ & 0.0108 & $\mathbf{0 . 0 2 0 7}$
\end{tabular}

Note: Bold (unbold) values denote the net information flow from exchange rates (stock markets) to stock markets (exchange rates).

the effect of true information from the "normal" pattern of returns. ${ }^{8}$

In each period, for each symbolic return series, we created $M=1000$ surrogate data to estimate the ETE and the relevant results are given in Tables 1 and 2 .

Table A.2 shows how using symbolic encoding partitions the data. As we see that the \%5 upper and lower threshold levels approximately correspond to the same standard deviations of the data in each period for each country. However, the effect of the crisis is observed on the minimum and maximum returns levels in terms of standard deviations. During the crisis period, standard deviations corresponding the minimum return levels significantly increases whereas the deviations corresponding to the maximum return levels drop significantly.

Table A.1 presents the optimal delay for each symbolic return series in each period and it reveals different patterns between countries. For example, for Latin American countries (Brazil, Chile and Mexico), optimal delay $k$ for exchange rate series significantly increases in the postcrisis period compared the pre-crisis era. This may be an evidence for the increased long memory in these financial time series which is likely to decrease the efficiency for these markets. On the other hand, we can not conclude a similar result for the stock markets. On the contrary, there are tendencies towards lower optimal $k$ values in general

\footnotetext{
8 Table A.2 shows 5\% of extreme returns (when transforming to the symbolic encoding) correspond to how many standard deviations. Qualitative results do not change when we take $10 \%$ as a cut-off point, however significance starts to decrease.
} 

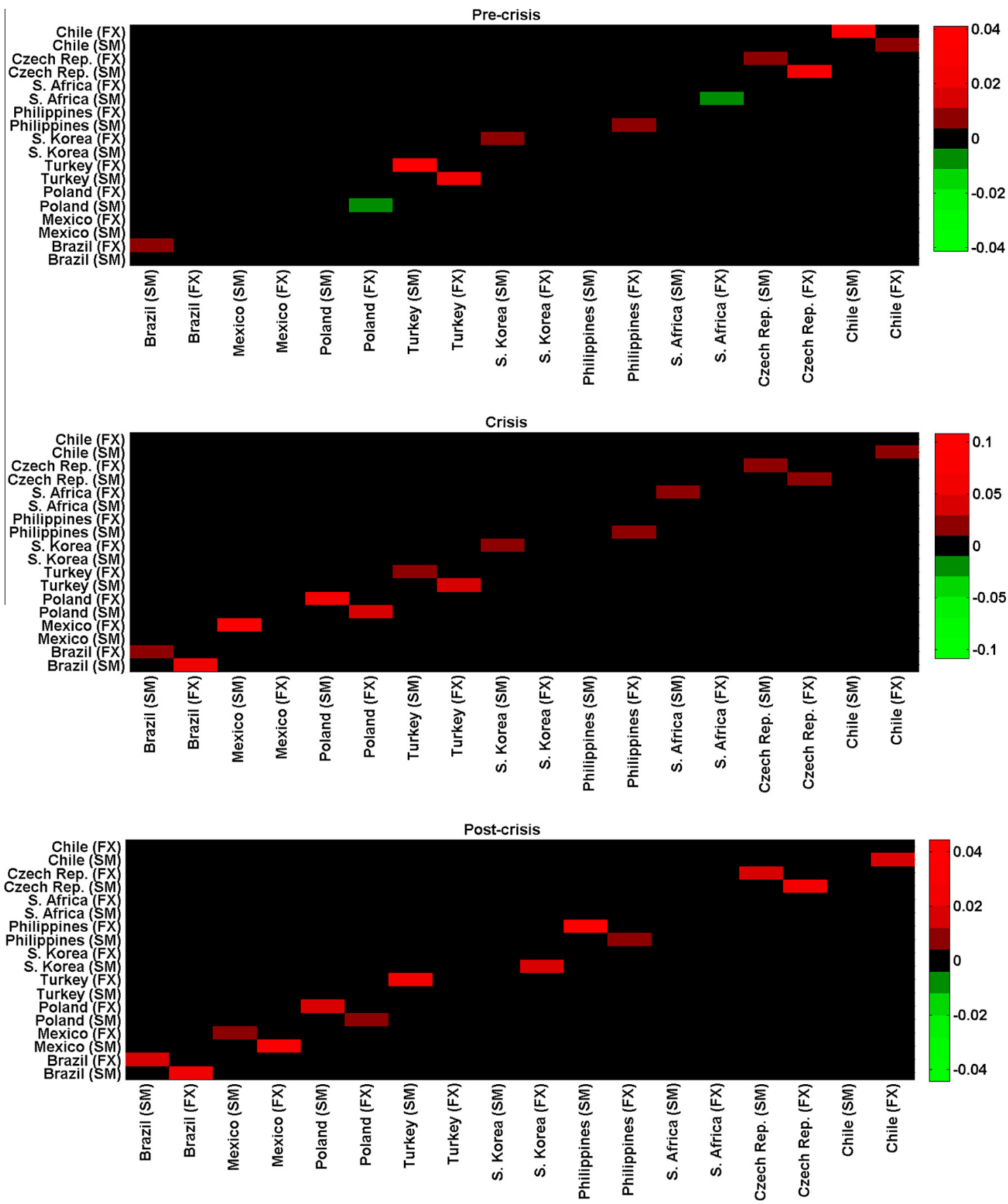

Fig. 1. Flow diagram of the effective transfer entropies between stock prices and exchange rates of each country. Flow is only from rows to columns. The focus is the interaction within a country therefore cross-country estimations are not performed.

if there is not a change. Such a situation may be an evidence for the recovery of emerging stock markets in terms of improved efficiency after the crisis. ${ }^{9}$

In the pre-crisis period, in 6/9 countries, there is no significant information flow between exchange rates and stock markets in any direction (see Table 1) i.e. the

\footnotetext{
${ }^{9}$ For a study supporting these arguments, see [11].
}

interaction between these two markets is only at low level. Regarding the remaining 3 countries, information flow is significant in both ways in Chile and Turkey. In Czech Republic, significance is only from stock market to exchange rate. Moreover, only in 3/9 countries, the net information flow is from stock prices to exchange rates (see Table 2) which shows that exchange rates dominates stock prices in general. 
During the crisis period, the situation starts to change: in $7 / 9$ countries, the information flow is significant in both ways i.e. the link between the two markets gets really strong during the crisis period (see Table 1). Only in Chile and Philippines, the information flow is significant in one direction and it is from stock market to exchange rates. Moreover, in 4/9 countries, the net information flow is from stock market to exchange rates, i.e. the effect of the financial crisis starts to show itself, the dominance of exchange rates and stock prices are almost symmetric.

In the post-crisis period, in all countries except South Africa, there exists at least unidirectional significant information flow. In 6/9 countries, the information flow from stock prices to exchange rates is significant and similarly, in 5/9 countries, the information flow from exchange rates to stock prices is significant. This picture implies that during in post-crisis period, the strong information link between these two markets continues to exist. Furthermore, in 6/9 countries, the net information flow is from stock markets to exchange rates (see Table 2), i.e. after the crisis, in general stock prices start to dominate exchange rates.

Fig. 1 displays the effective transfer entropies between the stock prices and exchange rates in each country and the aforementioned results are visually displayed here. Accordingly, the information flow is weak in the pre-crisis period. However, the crisis period significantly increases the interaction between these two variables (see the scale of the color-bar in crisis period); and the strong interaction continues after the crisis.

The overall results in Table 2 and Fig. 1 quantitatively and visually validate the increased integration between both markets in the emerging countries recently. Moreover, they confirm the expected asymmetry in the information flow between the stock prices and exchange rates in the post-crisis period: After the global financial crisis of 2008, the main indicator of the general mood of the financial markets have become stock markets all around the world. Therefore, views towards the economy are expected to be reflected initially in the stock market after the crisis, which is quantitatively shown in our analysis.

\section{Discussion and conclusion}

This paper uses the concept of transfer entropy to examine the information flow between exchange rates and stock markets in all emerging countries implementing inflation targeting and having floating currencies. The main advantages of the methodology are its easy implementation-interpretation by non-parametricity and ability to capture the non-linear dynamics. In the case where bidirectional significant information flow exist, it helps us to see the direction of the net flow. We believe this methodology constitutes a nice and promising alternative to the standard measures.

Although there exists some exceptions, the general conclusion is that exchange rates and stock markets interact only at low level in the pre-2008 global financial crisis period and in general the first dominates the latter. During the
Table A.1

Optimal delay $k$ for each symbolic currency and benchmark index return series ( $k$ is the value that produces the first local minimum of the MI for the corresponding series in the corresponding period).

\begin{tabular}{llll}
\hline Tickers & $\begin{array}{l}\text { Pre- } \\
\text { crisis }\end{array}$ & Crisis & $\begin{array}{l}\text { Post- } \\
\text { crisis }\end{array}$ \\
\hline USDBRL (Brazil - exchange rate) & 1 & 2 & 3 \\
IBOV (Brazil - stock market) & 1 & 1 & 2 \\
USDCLP (Chile - exchange rate) & 1 & 1 & 3 \\
IPSA (Chile - stock market) & 4 & 1 & 1 \\
USDCZK (Czech Republic - exchange rate) & 2 & 1 & 2 \\
PX (Czech Republic - stock market) & 4 & 1 & 1 \\
USDKRW (South Korea - exchange rate) & 3 & 3 & 2 \\
KOSPI (South Korea - stock market) & 1 & 1 & 1 \\
USDMXN (Mexico - exchange rate) & 1 & 1 & 3 \\
MEXBOL (Mexico - stock market) & 1 & 3 & 1 \\
USDPHP (Philippines - exchange rate) & 3 & 1 & 1 \\
PCOMP (Philippines - stock market) & 1 & 1 & 3 \\
USDPLN (Poland - exchange rate) & 3 & 3 & 1 \\
WIG (Poland - stock market) & 1 & 2 & 2 \\
USDZAR (South Africa - exchange rate) & 1 & 1 & 1 \\
JALSH (South Africa - stock market) & 1 & 1 & 1 \\
USDTRY (Turkey - exchange rate) & 2 & 2 & 1 \\
XU100 (Turkey - stock market) & 2 & 1 & 1 \\
\hline
\end{tabular}

crisis, the interaction between these two variables gets significantly strong in bidirectional ways in almost all countries. Interestingly, the aftermath of the crisis suggests qualitative changes: to the contrary of the pre-crisis period, the strong interaction between exchange rates and stock markets (appeared during the crisis) resists to continue and in general stock prices dominate exchange rates. This situation reveals a fact that is crucial for both investors and policy makers: After the crisis, there is a strong feedback in both ways thus using information on one market may help to forecast the behavior of the other. Also, information between markets is transmitted quickly and policy intervention may become more effective in the desired direction within reasonable time horizon. Moreover in emerging countries, expectations towards the economy are reflected initially in the stock market after the crisis. We interpret this situation as the investors heightened sensitivity to stock markets after the catastrophic results of the crisis; in particular foreign ${ }^{10}$ investors in emerging countries primarily adjust their general portfolio positions according to stock markets' movements.

\section{Acknowledgments}

We thank the anonymous referee for helpful comments and suggestions that significantly improved this paper.

\section{Appendix A. Supplementary results}

Tables A.1 and A.2.

\footnotetext{
${ }^{10}$ The assumption of foreign investors is based on the fact that stock market investments do not constitute a very significant portion of total household savings compared to other form of financial assets in most of the analyzed countries.
} 
Table A.2

Standard deviations corresponding to symbolic encoding of extreme returns.

\begin{tabular}{|c|c|c|c|c|c|c|c|c|c|c|c|c|}
\hline & \multicolumn{4}{|c|}{ Pre-crisis } & \multicolumn{4}{|l|}{ Crisis } & \multicolumn{4}{|c|}{ Post-crisis } \\
\hline & Min & $\begin{array}{l}\% 5 \\
\text { Lowest }\end{array}$ & $\begin{array}{l}\% 5 \\
\text { Highest }\end{array}$ & Max & Min & $\begin{array}{l}\% 5 \\
\text { Lowest }\end{array}$ & $\begin{array}{l}\% 5 \\
\text { Highest }\end{array}$ & Max & Min & $\begin{array}{l}\% 5 \\
\text { Lowest }\end{array}$ & $\begin{array}{l}\% 5 \\
\text { Highest }\end{array}$ & Max \\
\hline Brazil FX & 3.71 & 1.54 & 1.66 & 4.68 & 4.69 & 1.53 & 1.65 & 3.96 & 3.97 & 1.52 & 1.64 & 5.11 \\
\hline Brazil SM & 4.45 & 1.68 & 1.65 & 3.14 & 4.20 & 1.60 & 1.45 & 4.74 & 5.63 & 1.58 & 1.60 & 4.26 \\
\hline Chile FX & 3.98 & 1.61 & 1.71 & 3.28 & 3.61 & 1.49 & 1.77 & 4.53 & 3.53 & 1.59 & 1.62 & 6.87 \\
\hline Chile SM & 6.02 & 1.44 & 1.62 & 3.50 & 3.84 & 1.64 & 1.35 & 7.29 & 7.08 & 1.45 & 1.52 & 5.59 \\
\hline Czech Rep. FX & 4.11 & 1.70 & 1.67 & 3.51 & 6.14 & 1.33 & 1.74 & 3.31 & 3.86 & 1.61 & 1.75 & 3.44 \\
\hline Czech Rep. SM & 5.42 & 1.59 & 1.48 & 6.23 & 6.35 & 1.64 & 1.20 & 4.85 & 4.46 & 1.47 & 1.47 & 5.02 \\
\hline S. Korea FX & 6.24 & 1.60 & 1.49 & 3.89 & 9.00 & 1.52 & 1.57 & 6.98 & 6.26 & 1.49 & 1.60 & 4.25 \\
\hline S. Korea SM & 3.28 & 1.89 & 1.68 & 3.22 & 4.93 & 1.76 & 1.42 & 4.98 & 5.01 & 1.73 & 1.53 & 3.82 \\
\hline Mexico FX & 5.14 & 1.48 & 1.73 & 4.35 & 6.35 & 1.20 & 1.57 & 6.71 & 5.26 & 1.57 & 1.59 & 6.08 \\
\hline Mexico SM & 4.81 & 1.56 & 1.57 & 5.24 & 3.47 & 1.85 & 1.43 & 4.99 & 5.37 & 1.65 & 1.65 & 5.47 \\
\hline Philippines FX & 3.54 & 1.66 & 1.55 & 4.03 & 3.53 & 1.68 & 1.60 & 2.24 & 3.15 & 1.54 & 1.73 & 3.37 \\
\hline Philippines SM & 6.53 & 1.39 & 1.63 & 3.72 & 6.60 & 1.75 & 1.33 & 4.72 & 4.67 & 1.53 & 1.63 & 4.42 \\
\hline Poland FX & 3.95 & 1.58 & 1.61 & 4.53 & 4.83 & 1.46 & 1.69 & 3.81 & 3.28 & 1.50 & 1.65 & 4.09 \\
\hline Poland SM & 4.80 & 1.65 & 1.69 & 3.55 & 4.45 & 1.77 & 1.49 & 3.26 & 4.77 & 1.59 & 1.64 & 4.43 \\
\hline S. Africa FX & 2.92 & 1.50 & 1.86 & 3.48 & 3.89 & 1.31 & 1.50 & 9.09 & 4.04 & 1.55 & 1.66 & 6.16 \\
\hline S. Africa SM & 6.01 & 1.47 & 1.43 & 4.41 & 3.71 & 1.64 & 1.50 & 3.35 & 3.35 & 1.64 & 1.65 & 3.84 \\
\hline Turkey FX & 4.01 & 1.33 & 1.71 & 5.65 & 4.51 & 1.28 & 1.69 & 5.40 & 3.46 & 1.52 & 1.67 & 4.94 \\
\hline Turkey SM & 5.20 & 1.72 & 1.53 & 3.06 & 3.66 & 1.67 & 1.46 & 4.93 & 4.80 & 1.58 & 1.63 & 4.51 \\
\hline
\end{tabular}

Note: FX and SM stand for exchange rate and the stock market respectively.

\section{References}

[1] Fraser AM, Swinney HL. Independent coordinates for strange attractors from mutual information. Phys Rev A 1986;33: 1134-40.

[2] Granger CWJ. Investigating causal relations by econometric models and cross-spectral methods. Econometrica 1969;37:424-38.

[3] Hiemstra C, Jones JD. Testing for linear and non-linear Granger causality in the stock price-volume relation. J Financ 1994;49:1639-64.

[4] Jizba P, Kleinert H, Shefaat M. Renyi's information transfer between financial time series. Phys A 2012;91:2971-89.

[5] Kwon O, Oh G. Asymmetric information flow between market index and individual stocks in several stock markets. Europhys. Lett. 2012;97:28007.

[6] Kwon O, Yang JS. Information flow between composite stock index and individual stocks. Phys A 2008;387:2851-6.
[7] Kwon O, Yang JS. Information flow between stock indices. Europhys. Lett. 2008;82:68003.

[8] Marschinski R, Kantz H. Analysing the information flow between financial time series: an improved estimator for transfer entropy. Eur Phys J B 2002;30:275-81.

[9] Reddy YV, Sebastin A. Interaction between forex and stock markets in india: an entropy approach. Vikalpa 2008;33:27-45.

[10] Schreiber T. Measuring information transfer. Phys Rev Lett 2000;85:462-4.

[11] Sensoy, A. Efficency of stock markets and exchange rates: Emerging vs. developed countries. Borsa Istanbul Working Paper Series 11; 2013.

[12] Shannon CE. A mathematical theory of communication. Bell Syst Tech J 1948;27:379-423.

[13] Theiler J, Galdrikian B, Longtin A, Eubank S, Farmer JD. Testing for non-linearity in time series: the method of surrogate data. Phys D 1992;58:77-94. 